\title{
Behavior of Neonate Diamondback Moth Larvae (Lepidoptera: Plutellidae) on Glossy-Leafed Resistant Brassica oleracea L.
}

\author{
SANFORD D. EIGENBRODE AND ANTHONY M. SHELTON \\ Department of Entomology, New York State Agricultural Experiment Station, \\ Cornell University, Geneva, New York 14456
}

\begin{abstract}
Environ. Entomol. J9(5): 1566-1571 (1990)
ABSTRACT The dispersal and survival of neonate diamondback moth larvae, Plutella xylostella (L.), were measured on normal bloom susceptible 'Round-Up' cabbage and a resistant genotype descended from glossy cauliflower, PI 234599. During the first $24 \mathrm{~h}$ after hatching, neonate $P$. xylostella dispersed more rapidly and initiated fewer mines on the resistant glossy 2518 than on 'Round-Up.' Also, a greater proportion of neonates were found dead on 2518 than on 'Round-Up.' Individual neonates had significantly higher movement rates on three glossy resistant genotypes of Brassica oleracea than on two normal bloom types. Movement rates were negatively correlated with percentage of larvae surviving to fourth instar. Removal of leaf epicuticular waxes with dichloromethane or disruption of the wax morphology eliminated the difference in movement rate on 'Round-Up' and 8329, a glossy cabbage descended from PI 234599 . Headspace vapor of 8329 or 'Round-Up' plants did not affect movement rates of neonate $P$. xylostella. The results indicate that wax morphology is of primary importance in producing increased larval movement rates on glossy resistant lines. Wax chemistry may also contribute to the effect. Neonate nonpreference for leaf wax characteristics is proposed as the mechanism of resistance to $P$. xylostella in glossy B. oleracea.
\end{abstract}

KEY WORDS Insecta, Plutella xylostella, Brassica oleracea, host plant resistance

MORE THAN A DECADE of work on lepidopteran resistance in crucifers at the New York State Agricultural Experiment Station, Geneva, has produced lines with resistance to the diamondback moth, Plutella xylostella (L.), a serious pest of crucifers throughout the world (Dickson \& Eckenrode. 1980, Lin et al. 1984, Shelton et al. 1988). In a previous report (Eigenbrode et al. 1990) we noted evidence for two types of resistance that lower survival of $P$. xylostella on the Geneva breeding lines, one type of resistance in lines whose leaves have the typical wax bloom of cultivated Brassica oleracea (normal bloom) and the other in glossyleafed lines descended from an Australian cauliflower, PI 234599. Polar fractions of ethanol extracts of two normal bloom resistant lines increased mortality of $P$. xylostella larvae when added to artificial diet. No such extractable material was detected in a glossy-leafed descendent of PI 234599, which was highly resistant to $P$. xylostella in the field. The resistance in the glossy line was attributed to unknown factors. However, we reported that dispersal of neonate $P$. xylostella was apparently greater on the glossy type than on normal bloom resistant lines, suggesting a behavioral resistance mechanism.

In this report, we examine the link between larval dispersal, larval feeding, and resistance in glossy cabbages. We also measure movement rates of in- dividual neonates on glossy resistant and normalbloom susceptible cabbage to determine if these rates reflect resistance levels in the genotypes. Finally, we investigate the specific factors influencing movement rates of neonates on resistant glossy lines.

\section{Materials and Methods}

Plants and Insects. Cabbage lines (Brassica oleracea var. capitata) investigated from the Geneva crucifer breeding program were New York accessions 2518, 8329, 3891, and 2535; all are descended from glossy-leafed cauliflower PI 234599, and all are glossy-leafed types, except 2535 which has normal bloom. The normal bloom susceptible commercial hybrid 'Round-Up' was used as a control. A collard (Brassica oleracea var. acephala), PI 261597, with a different gene for glossy leaf than PI 234599 (M. H. Dickson, personal communication), was included in one experiment.

Plants were started in flats in the greenhouse during June 1988 and transplanted after 7-8 wk, at the Vegetable Research Farm of the New York State Agricultural Experiment Station, near Geneva. Test lines were transplanted into a completely randomized design consisting of three blocks of eight 10-plant replicate plots per block. In each block 'Round-Up' was replicated twice to provide additional control material, and the other six genotypes were replicated once. Plants were spaced 
$45 \mathrm{~cm}$ apart within the rows and $90 \mathrm{~cm}$ between rows. All experiments were conducted when plants had been in the field for $>6 \mathrm{wk}$ and before head formation. To confirm resistance in these genotypes, a sample of plants from each was inoculated with $200 P$. xylostella eggs on 1 August and evaluated at fourth instar (16 August) for percentage of larvae surviving. Data were angularly transformed and then analyzed using analysis of variance. When analysis indicated significant differences among the genotypes, means were separated using least significant differences $(\alpha=0.05)$ so that the test was a "protected" LSD (Snedecor \& Cochran 1980).

Eggs or neonate larvae for all tests were obtained from a laboratory colony established with insects collected in 1987, near Geneva, and maintained for $\approx 20$ generations before testing

Distribution of Larvae on Whole Plants in the Field. Sets of $\approx 1,000 P$. xylostella eggs, on foil sheets, were incubated in $235 \mathrm{ml}$ paper cups at $37^{\circ} \mathrm{C}$ and $60 \% \mathrm{RH}$ until larvae were just beginning to emerge. Plants at the 20-leaf stage, of resistant 2518 and susceptible 'Round-Up,' were inoculated by attaching an egg sheet and paper cup with emerging larvae to the approximate eighth leaf of each plant. Each plant was fitted with a cardboard or polyethylene collar $(40 \mathrm{~cm}$ diameter, $20 \mathrm{~cm}$ high) coated with Sticky Stuff (Olson Products, Inc., Medina, Ohio), and sealed tightly around the plant stem to trap larvae leaving or falling from the plants. At 3 and $24 \mathrm{~h}$ after inoculation, the total number of larvae, alive and dead, and the number of mines were counted on each plant. The number of larvae trapped on the collars also was counted. The total number of larvae initially infesting each plant was determined by subtracting the number of larvae that had not left the inoculating cup from the number of hatched eggs (empty chorions). The experiment was repeated twice, starting on 5 and 16 August. In each experiment, three plants of each variety were evaluated at each time. The results of the two experiments were combined for analysis and Student's $t$ test was used to compare mean values for total number of larvae placed on the plants, percentage of larvae surviving, proportions of larvae lost and leaving the plant, and mines per larva.

To measure dispersal rates on resistant and susceptible plants in this experiment, the number of larvae recovered on each leaf, and that leaf's position relative to the inoculated leaf, also were recorded. Larval dispersal on each plant was then quantified by a dispersal index (DI), calculated as $\sum_{i=1}^{k} p_{i}\left(L_{i}\right)$, where $p_{i}$ is the proportion of larvae found on leaf $i, L_{i}$ is the leaf position relative to the inoculated leaf, and $k$ is the total number of leaves on the plant. The inoculated leaf has an $L_{i}$ of 0 ; leaves adjacent to the inoculated leaf have $L_{1} s$ of 1 , and so on. The index has a value of 0 if no larvae disperse from the inoculated leaf. The maximum value of $\mathrm{DI}$ equals the largest $L_{t}$ on the plant (for the plants in this study, $\approx 15$ ) but only occurs if all larvae disperse to the leaf most distant from the inoculated leaf, which never occurred in this experiment. The DIs for the two plant genotypes at each sample time were determined and compared within each experiment using Student's $t$ test.

Movement Rates of Individual Neonates in the Field. Individual larvae, $<1 \mathrm{~h}$ old, obtained from incubated egg sheets, as above, were placed on the abaxial side of leaves of 2518 and 'Round-Up' in the field and observed for $1 \mathrm{~h}$, or until the larva left the leaf. Larvae were handled by allowing them to descend on a strand of silk and intercepting the silk with a paint brush; thus the animals were never touched during transfer. After transfer, the location of the larva was recorded on an acetate template of the leaf at 5-min intervals for $1 \mathrm{~h}$. The number of larvae establishing a feeding site or leaving the leaf was recorded. A total of 57 larvae were observed on 2518, and 59 on 'Round-Up' between 5 and 25 August. A maximum of five larvae was observed on each leaf and 12 leaves were used for each line. The acetate records were used to calculate movement rates in $\mathrm{cm} / \mathrm{min}$, which were compared using Student's $t$ test. The number of larvae establishing feeding sites and leaving the leaf was compared using $\chi^{2}$ analysis.

Movement Rates of Individual Neonates in the Laboratory. Middle-aged leaves were removed from plants in the field and their petioles were placed immediately in water-filled tubes. Within $\mathrm{l} \mathrm{h}$ after leaf excision, groups of 12 neonate larvae ( $<1 \mathrm{~h}$ after hatch) were placed on the abaxial surface of a test leaf and their movements recorded for $5 \mathrm{~min}$, at $22^{\circ} \mathrm{C}$, using a camcorder equipped with a macro lens. The light source for recording was a $40-W$ incandescent lamp placed behind the leaf. Larvae were confined on test leaves in an arena $(3.5$ by $2.0 \mathrm{~cm}$ ) with a barrier of silicone vacuum grease. Each group of larvae was recorded for 5 min. Larval tracks were traced onto acetate sheets placed on a monitor screen during replay. The tracks were retraced on a digitizing tablet and the path length and movement rate in $\mathrm{cm} / \mathrm{min}$ for each larva were determined. This system was used to record larval movement rates in experiments 1 through 4 described below. Unless otherwise noted, each experiment was completed during a single recording session using one cohort of hatching larvae to reduce within-treatment variation.

Experiment 1: Glossy and Normal-Bloom Genotypes. Larvae were recorded on leaves of cabbages $8329,3891,2535$, and 'Round-Up,' and collard PI 261597. Approximately 40 larvae were recorded on each genotype. Resistance levels in plants used for these assays were estimated immediately preceding the behavioral tests by inoculating 12 plants of each genotype and measuring survival as described above (inoculated 20 August, evaluated 30 August 1988). 
Table 1. Percentage of $P$. xylostella larvae surviving to fourth instar on five Brassica oleracea genotypes in the field at Geneva, N.Y.

\begin{tabular}{lcc}
\hline Genotypes & \% Survivala & $\begin{array}{c}\text { No. plants } \\
\text { inoculated }^{b}\end{array}$ \\
\hline Normal bloom & & \\
'Round-Up' & $31.14 \pm 2.56 \mathrm{a}$ & 36 \\
2535 & $18.55 \pm 1.43 \mathrm{~b}$ & 31 \\
Glossy & & \\
PI 261597 & & \\
(collards) & $13.83 \pm 1.6 \mathrm{lb}$ & 12 \\
3891 & $2.73 \pm 0.59 \mathrm{c}$ & 15 \\
8329 & $0.65 \pm 0.16 \mathrm{~d}$ & 26 \\
2518 & $0.0 \pm 0.0 \mathrm{e}$ & 12 \\
\hline
\end{tabular}

a Means $( \pm \mathrm{SE})$ with the same letter are not significantly different $(\alpha=0.05 ; \mathrm{LSD})$. Analysis of variance: $F=47.82 ; \mathrm{df}=5,126 ; P$ $=0.0001$.

${ }^{b}$ Each plant inoculated with 200 eggs.

Experiment 2: Solvent Removal of Epicuticular Waxes. Epicuticular leaf waxes were removed from half of a sample of leaves of 'Round-Up' and glossy resistant 8329 with 10-s dips in three consecutive baths of dichloromethane. Movement rates were recorded on waxed leaves and dewaxed leaves immediately after the solvent had evaporated from the leaf. Approximately 40 larvae were recorded on each treatment.

Experiment 3: Mechanical Polishing of Epicuticular Waxes. Epicuticular leaf waxes were polished on half of a sample of leaves of 'Round-Up' and glossy resistant 8329 with dry cotton swabs. The procedure destroys the complex crystalline structure of the epicuticular waxes on normal glaucous leaves but has little effect on waxes of glossy types. 'Round-Up' leaves were polished until they resembled 8329 in bloom, and leaves of the glossy plants were polished with a similar number of strokes. Movement rates of $\approx 40$ larvae were recorded on each treatment (see Table 5 for exact number).

Experiment 4: Headspace Vapor. Entire, individual plants of 8329 and 'Round-Up' were cut off at the soil surface, placed with cut stems immersed in distilled water in a 15-liter sealed desiccating jar, and held for $3 \mathrm{~h}$. During this time a mixture of volatiles and gasses, referred to as headspace vapor, are generated by the plant tissue (Cole \& Finch 1978). A stream of humidified, charcoalfiltered air was passed through the desiccating jar and into a cylindrical Plexiglas chamber $(10 \mathrm{~cm}$ diameter by $10 \mathrm{~cm}$ high). The only exit for displaced headspace vapor from the desiccating jar was through a 3.5-by-2.0-cm opening covered with fine nylon organdy (mesh $130 / \mathrm{cm})$. A ring of silicone grease confined the larvae on this organdy and their movements were recorded and quantified as described above. A separate chamber was used for each plant type and controls were on organdy in clean air, humidified and filtered as above. Three separate recording sessions were performed using this design, for a total of 60-90 larvae per treatment and three plants per line.

Data from experiments 1 and 4 were analyzed using the General Linear Models Procedure in SAS (SAS Institute 1985, p. 433) to perform analysis of variance. When the analysis indicated significant differences among the genotypes, means were separated using least significant differences $(\alpha=0.05)$ so that the test was a "protected" LSD (Snedecor \& Cochran 1980). In experiments 2 and 3, Student's $t$ was used to compare movement rates on the two genotypes for each treatment. In experiment 4, planned contrasts were made, as described in the results for that experiment.

\section{Results}

The percentage of $P$. xylostella surviving to fourth instar differed significantly among the genotypes and ranged from $30 \%$ on the susceptible control 'Round-Up' to $<1 \%$ on resistant glossies 8329 and 2518 (Table 1). This confirms expression of resistance in the genotypes of Brassica oleracea used in these experiments.

Distribution of Larvae on Whole Plants in the Field. The proportion of larvae recovered dead

Table 2. Comparison of P. xylostella larval mortality and mining on susceptible 'Round-Up' (R-Up) and glossy resistant 2518 cabbage in the field

\begin{tabular}{|c|c|c|c|c|c|c|c|c|c|c|c|}
\hline \multicolumn{2}{|c|}{$\begin{array}{l}\text { Initial no. } \\
\text { larvae/plant }\end{array}$} & \multicolumn{2}{|c|}{$\begin{array}{l}\text { Proportion } \\
\text { lost/plant }\end{array}$} & \multicolumn{2}{|c|}{$\begin{array}{l}\text { Proportion } \\
\text { dead/plant }\end{array}$} & \multicolumn{2}{|c|}{ Mines/larva/plant } & \multicolumn{2}{|c|}{$\begin{array}{l}\text { Proportion } \\
\text { leaving plant }\end{array}$} & \multicolumn{2}{|c|}{$\begin{array}{c}\text { Proportion } \\
\text { lost + dead/ } \\
\text { plant (estimated } \\
\text { mortality) }\end{array}$} \\
\hline H-Up & 2518 & R-Up & 2518 & R-Up & 2518 & R-Up & 2518 & R-Up & 2518 & $\mathrm{R}-\mathrm{Up}_{\mathrm{p}}$ & 2518 \\
\hline \multicolumn{12}{|c|}{$3 \mathrm{~h}$ after inoculation } \\
\hline $\begin{array}{l}250.8 \\
(20.1)\end{array}$ & $\begin{array}{l}241.8 \\
(39.3)\end{array}$ & $\begin{array}{c}0.097 \\
(0.112)\end{array}$ & $\begin{array}{c}0.00 \\
(0.00)\end{array}$ & $\begin{array}{c}0.021^{*} \\
(0.007)\end{array}$ & $\begin{array}{c}0.073 \\
(0.015)\end{array}$ & $\begin{array}{c}0.71 \\
(0.08)\end{array}$ & $\begin{array}{c}0.60 \\
(0.11)\end{array}$ & $\begin{array}{c}0.034 \\
(0.024)\end{array}$ & $\begin{array}{c}0.055 \\
(0.022)\end{array}$ & $\begin{array}{l}0.118^{*} \\
(0.105)\end{array}$ & $\begin{array}{c}0.073 \\
(0.015)\end{array}$ \\
\hline \multicolumn{12}{|c|}{$24 \mathrm{~h}$ after inoculation } \\
\hline $\begin{array}{l}422.0 \\
(89.5)\end{array}$ & $\begin{array}{l}603.0 \\
(51.8)\end{array}$ & $\begin{array}{r}0.235^{*} \\
(0.168)\end{array}$ & $\begin{array}{c}0.584 \\
(0.038)\end{array}$ & $\begin{array}{l}0.075^{* * *} \\
(0.022)\end{array}$ & $\begin{array}{c}0.301 \\
(0.038)\end{array}$ & $\begin{array}{l}3.96^{* * * *} \\
(0.46)\end{array}$ & $\begin{array}{c}0.46 \\
(0.43)\end{array}$ & $\begin{array}{c}0.034 \\
(0.007)\end{array}$ & $\begin{array}{c}0.069 \\
(0.019)\end{array}$ & $\begin{array}{r}0.254^{*} \\
(0.148)\end{array}$ & $\begin{array}{c}0.704 \\
(0.034)\end{array}$ \\
\hline
\end{tabular}

Probability of smaller $P$ value for Student's $t$ test comparing means (SE) for 'Round-Up' and 2518 for each statistic at each sample time: $*, P<0.05 ; * * *, P<0.001$. Pairs with no mark are not significantly different. 


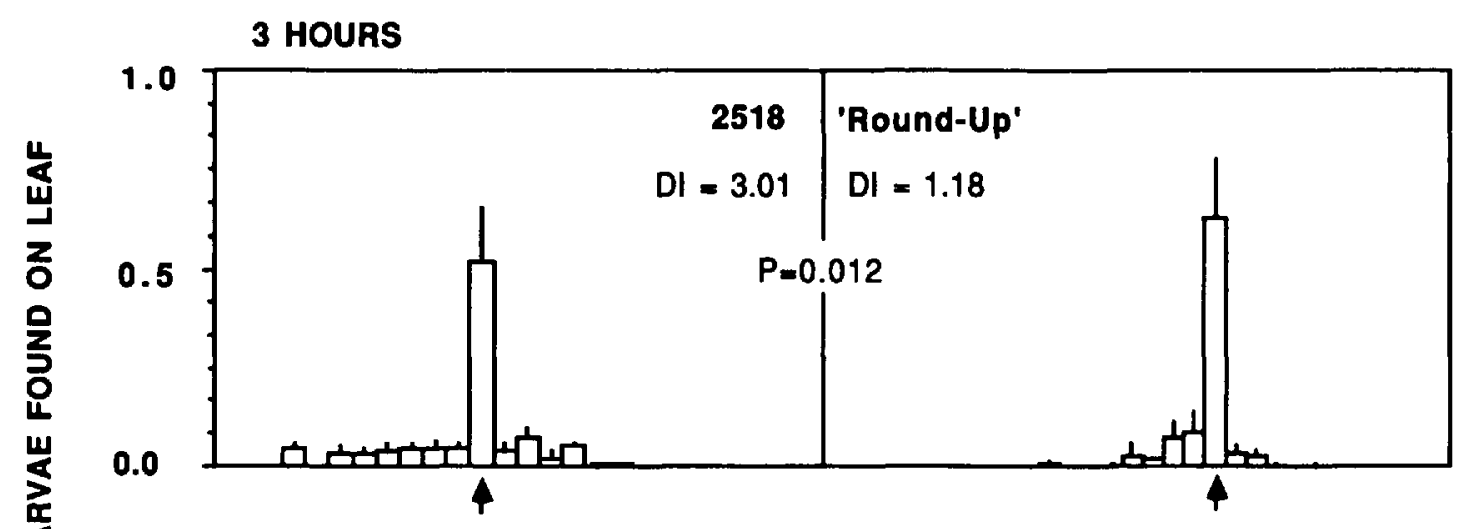

24 HOURS

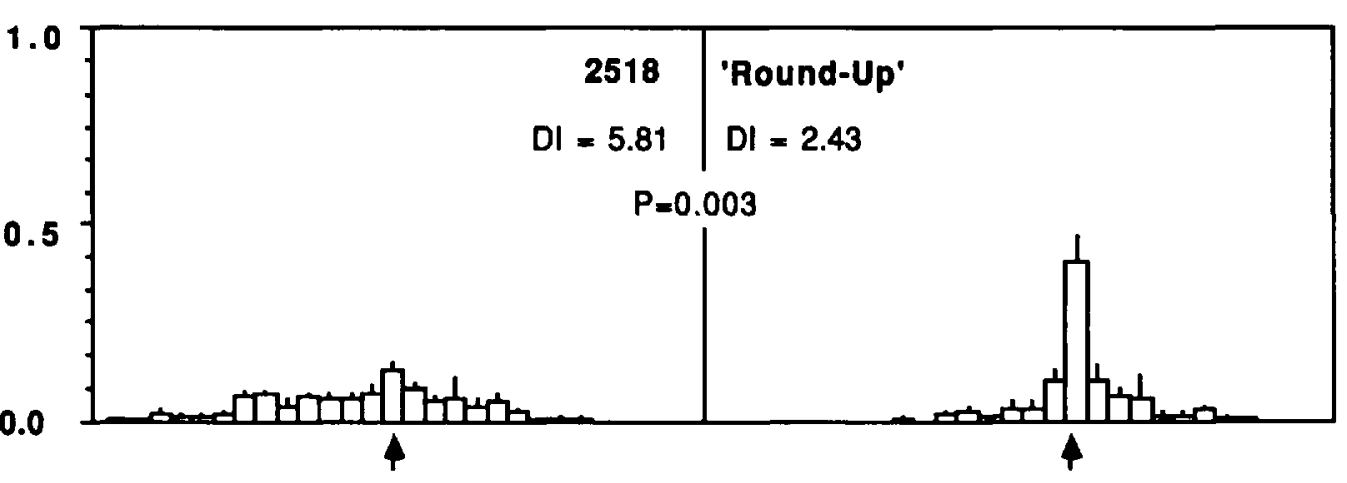

LEAF POSITION

Fig. 1. Dispersal of $P$. xylostella larvae over $24 \mathrm{~h}$ on glossy resistant 2518 and normal-bloom susceptible 'RoundUp.' Heights of bars represent the mean proportion of total larvae recovered from individual leaves (error bars = SEM). Bars marked with arrows represent leaves inoculated with 200-600 larvae at time zero (see Table 2). Bars to the left of the arrows represent leaves of decreasing age relative to the inoculated leaf; those to the right of the arrows represent leaves of increasing age relative to the inoculated leaf. The $P$ value given in each panel is based on Student's $t$ comparing mean DI for 2518 and 'Round-Up' at each time.

was greater on 2518 at both census times and the number of mines per larva was significantly greater on 'Round-Up' $24 \mathrm{~h}$ after hatch (Table 2). Also, the mean proportion of larvae unaccounted for ("lost" in Table 2) was higher for 2518 in the 24-h sample. The proportion of larvae lost (as high as 58\%) may include insects that died within mines or whose carcasses were difficult to identify amid other debris on the plant. If the larvae lost are presumed to be dead, a new value, estimated mortality, can be calculated, which is also significantly higher on 2518 at $24 \mathrm{~h}$ (Table 2).

Larval dispersal from the point of inoculation was greater on 2518 than on susceptible 'RoundUp' (Fig. 1). At both sample times the dispersal index on 2518 is significantly greater than on 'Round-Up.' Despite differences in dispersal within plants, the proportion of recovered larvae leaving plants did not differ significantly between the genotypes (Table 2).

In these experiments, the number of larvae initially infesting the plants did not differ between the lines but was higher in plants evaluated at 24 $\mathrm{h}$ as compared with $3 \mathrm{~h}$ (Table 2). This difference in infestation is due to fewer insects having left the inoculating cup at $3 \mathrm{~h}$. Although substantial, the difference is not likely to affect the interpretation of the results (due to possible crowding of larvae), because the plant resource is vast compared with the tiny neonate larvae.

Movement Rates of Individual Neonates in the Field. Larvae observed for $1 \mathrm{~h}$ moved significantly faster on 2518 than on 'Round-Up' (Table 3). Within $1 \mathrm{~h}$, larvae also left glossy leaves significantly more frequently and established fewer feeding sites on 2518 than on 'Round-Up.' The latter difference is not significant at $\alpha=0.05$ but is consistent with large differences in mines per larvae after $24 \mathrm{~h}$ in the whole-plant experiment (Table 2).

Movement Rates of Individual Neonates in the Laboratory. In the laboratory experiments, larvae were recorded for $5 \mathrm{~min}$ rather than $1 \mathrm{~h}$ as in the above field experiment. Larval movement rates are greater during 1-h observations, because larvae en- 
Table 3. Movement rates $(\mathrm{cm} / \mathrm{min} \pm \mathrm{SE}$ ) of individual P. xylostella neonates, number establishing feeding sites, and number leaving leaf in the field on glossy resistunt 2518 and susceptible 'Round-Up' cabbage

\begin{tabular}{lcccc}
\hline \hline Genotype & $\begin{array}{c}\text { No. } \\
\text { larvae }\end{array}$ & $\begin{array}{c}\text { Movement } \\
\text { rate }^{a}\end{array}$ & $\begin{array}{c}\text { No. } \\
\text { feeding }^{b}\end{array}$ & $\begin{array}{c}\text { No. } \\
\text { leaving }\end{array}$ \\
\hline 2518 & 57 & $1.56 \pm 0.23$ & 11 & 23 \\
'Round-Up' & 51 & $0.56 \pm 0.07$ & 20 & 7 \\
\hline
\end{tabular}

a Student's $\boldsymbol{t}$ test; $P=0.0001$

${ }^{b} \chi^{2}$ analysis, $P=0.059$; not significant.

$c \chi^{2}$ analysis, $P=0.01$.

gage in longer uninterrupted explorations after the initial $5 \mathrm{~min}$.

Experiment 1: Glossy and Normal-Bloom Genotypes. Movement rates of $P$. xylostella neonates differed significantly among the genotypes (Table 4). Rates were lower on normal bloom susceptible 'Round-Up,' and normal bloom resistant 2535 than on glossy genotypes. The percentage of larvae surviving to fourth instar also differed significantly among the genotypes. Movement rate was negatively correlated with percentage of larvae surviving on the five genotypes $\left(R=-0.833 ; R^{2}=0.781\right.$; $\mathrm{df}=4 ; P<0.02$ ).

Experiment 2: Solvent Removal of Epicuticular Waxes. Removal of epicuticular waxes with dichloromethane eliminated behavioral differences between glossy 8329 and 'Round-Up' (Table 5). Dewaxing increased larval movement rates on 'Round-Up' and decreased them on 8329 so that movement rates on dewaxed leaves of both genotypes were statistically equivalent.

Experiment 3: Mechanical Polishing of Epicuticular Waxes. Mechanical polishing of leaf waxes also eliminated behavioral differences between glossy 8329 and 'Round-Up' (Table 5). Polishing resulted in increased movement rates of $P$. xylostella neonates on 'Round-Up' but did not affect them on 8329 , so that movement rates on polished

Table 4. Percentage of $P$. xylostella surviving to fourth instar and movement rates of neonates $(\mathrm{cm} / \mathrm{min})$ on five genotypes of Brassica oleracea

\begin{tabular}{lcccc}
\hline \hline Genotypes & $\begin{array}{c}\% \\
\text { Sur- } \\
\text { vival }^{a}\end{array}$ & $\begin{array}{c}\text { No. } \\
\text { plants } \\
\text { inocu- } \\
\text { lated }\end{array}$ & $\begin{array}{c}\text { Movement } \\
\text { rate } \\
\text { cm/min }\end{array}$ & $\begin{array}{c}\text { No. } \\
\text { lar- } \\
\text { vae }\end{array}$ \\
\hline Normal Bloom & & & & \\
'Round-Up' & $30.83 \pm 2.18 \mathrm{a}$ & 12 & $0.12 \pm 0.01 \mathrm{c}$ & 39 \\
2535 & $14.17 \pm 1.56 \mathrm{~b}$ & 12 & $0.15 \pm 0.02 \mathrm{c}$ & 40 \\
Glossy & & & & \\
PI 261597 & $9.22 \pm 1.08 \mathrm{c}$ & 12 & $0.37 \pm 0.04 \mathrm{~b}$ & 21 \\
3891 & $2.22 \pm 0.41 \mathrm{~d}$ & 12 & $0.41 \pm 0.05 \mathrm{~b}$ & 38 \\
8329 & $0.78 \pm 0.16 \mathrm{~d}$ & 12 & $0.53 \pm 0.05 \mathrm{a}$ & 36 \\
\hline
\end{tabular}

Means ( $\pm S E$ ) with same letter in a column are not significantly different $(\alpha=0.05$; LSD $)$

analysis of variance $F=23.45 ; \mathrm{df}=4,55 ; P=0.0001$.

${ }^{b}$ Analysis of variance $F=91.9 ; \mathrm{df}=4,169 ; P=0.0001$.

c Each plant inoculated with 200 eggs.
Table 5. Movement rates of neonate $P$. xylostella on leaves of susceptible 'Round-Up' and resistant glossy $\mathbf{8 3 2 9}$ in experiments 2 and 3

\begin{tabular}{lcccccc}
\hline \hline & \multicolumn{2}{c}{ 'Round-Up' } & & \multicolumn{2}{c}{8329} \\
\cline { 2 - 3 } \cline { 5 - 6 } & $\begin{array}{c}\mathrm{cm} / \mathrm{min}, \\
\bar{x} \pm \mathrm{SE}\end{array}$ & $n$ & $\begin{array}{c}\mathrm{cm} / \mathrm{min}, \\
\bar{x} \pm \mathrm{SE}\end{array}$ & $n$ & \\
\hline Experiment $2^{a}$ & & & & & \\
Untreated & $0.13 \pm 0.01$ & 42 & $0.51 \pm 0.05$ & 35 & 0.0001 \\
Dewaxed & $0.26 \pm 0.02$ & 36 & $0.27 \pm 0.05$ & 40 & $\mathrm{NS}$ \\
Experiment $3^{b}$ & & & & & \\
Untreated & $0.29 \pm 0.03$ & 35 & $0.52 \pm 0.06$ & 42 & 0.0001 \\
Polished & $0.49 \pm 0.05$ & 35 & $0.58 \pm 0.07$ & 43 & $\mathrm{NS}$ \\
\hline
\end{tabular}

$n$, numbers of larvae tested in each treatment.

Analysis of variance: $F=32.99 ; \mathrm{df}=3,149 ; P=0.0001$.

${ }^{b}$ Analysis of variance: $F=4.57$; df $=3,151 ; P=0.0034$.

${ }^{c} P$ value for Student's $t$ comparing movement rate on 'RoundUp' and 8329.

leaves of both genotypes were statistically equivalent (Table 5). The relatively high rate of movement on 'Round-Up' in this experiment may have resulted from the sample of leaves used, which was slightly older than that used for experiment 2 . Nevertheless it is still significantly lower than movement rate on resistant types of the same age.

Experiment 4: Headspace Vapor. Movement rates of larvae in plant vapor (pooled data for both genotypes) were not significantly different from the clean air control $(0.66 \pm 0.01$ versus $0.72 \pm 0.05$ $\mathrm{cm} / \mathrm{min}$ in controls; $P=0.76$, comparison $F=$ 0.180 ; df $=1,310$ ); nor were there significant differences for 'Round-Up' vapor versus controls ( 0.64 \pm 0.05 versus $0.73 \pm 0.06 \mathrm{~cm} / \mathrm{min}$ in controls $)$, or 8329 vapor versus control $(0.68 \pm 0.04$ versus 0.71 $\pm 0.04 \mathrm{~cm} / \mathrm{min}$ on controls).

\section{Discussion}

Resistance to $P$. xylostella in the genotypes studied is associated with greater dispersal rates, reduced establishment of feeding sites, and higher mortality of first instars on glossy resistant plants than on susceptible controls. Additionally, the movement rate of individual larvae is significantly correlated with percentage of larvae surviving in these genotypes. These observations, along with Lin et al.'s (1983) finding that resistance in glossy plants is only effective against first-instar $P$. $x y l o-$ stella, suggest that the mechanism of resistance in glossy genotypes is rejection of the plants by first instars, which results in protracted searching behaviors (resulting in higher net movement rates), and reduced feeding. These behavioral differences may lead to increased larval mortality on glossy plants due to starvation and desiccation. Additionally, feeding of first instars normally results in the creation of mines (Salinas 1984). Failure to establish shelter within mines on glossy plants results in larvae remaining exposed on leaf surfaces, which is likely to increase the risk of desiccation, drowning, predation, and other causes of mortality. 
The headspace vapor from cabbage plants does not affect the movement rates of $P$. xylostella neonates and do not appear to be involved in the resistance of glossy plants. The epicuticular waxes of glossy plants, however, do cause increased movement rates of neonates. Removal of these waxes eliminates differences in movement rates of $P$. $x y$ lostella larvae on resistant and susceptible plants. The waxes of normal bloom, susceptible leaves also appear to act as a behavioral arrestant for the larvae because their removal produces an increase in larval movement rates; polishing normal glaucous plants results in high rates of larval movement, similar to those on glossy resistant plants. Although the existence of allelochemical constituents of the leaf epicuticular waxes may contribute to the behavioral response, our results indicate that morphological characteristics of the leaf waxes are of primary importance in eliciting increased movement on resistant glossy Brassica oleracea. The results of our studies suggest that the mechanism of resistance to diamondback moth in glossy Brassica oleracea is nonpreference by neonates in response to leaf wax characteristics of the plants.

\section{Acknowledgment}

We thank W. T. Wilsey, B. Burgess, and L. Mauro for assistance in the field and laboratory. M. H. Dickson, D. Pimentel, J. A. A. Renwick, J. Steffens, W. M. Tingey, J. T. Trumble, and M. G. Villani reviewed earlier drafts of the manuscript. The research was supported in part by the New York Cabbage Research Association, an A. W. Mellon Student Research Grant, and a Sigma Xi Student Grant-In-Aid of Research to S.D.E.

\section{References Cited}

Cole, R. A. \& S. Finch. 1978. Vapours from intact plants. Rep. Nat. Veg. Res. Stn. 1977: 84.

Dickson, M. H. \& C. J. Eckenrode. 1980. Breeding for resistance in cabbage and cauliflower to cabbage looper, imported cabbageworm, and diamondback moth. J. Am. Soc. Hortic. Sci. 105: 782-785.

Eigenbrode, S. D., A. M. Shelton \& M. H. Dickson. In press. Two types of resistance to the diamondback moth (Lepidoptera: Plutellidae). Environ. Entomol.

Lin, J., C. J. Eckenrode \& M. H. Dickson. 1983. Variation in Brassica oleracea resistance to diamondback moth (Lepidoptera: Plutellidae). J. Econ. Entomol. 76: 1423-1427.

Lin, J., M. H. Dickson \& C. J. Eckenrode. 1984. Resistance of Brassica lines to the diamondback moth (Lepidoptera: Yponomeutidae) in the field, and inheritance of resistance. J. Econ. Entomol. 77: 12931296.

Salinas, P. J. 1984. Studies on the behavior of the larvae of Plutella xylostella (Linnaeus) (Lepidoptera: Plutellidae), a world pest of cruciferous crops. Normal and spacing behavior. Turrialba 34: 77-84.

SAS Institute. 1985. SAS user's guide: statisties, version 5 ed. SAS Institute, Cary, N.C.

Shelton, A. M., C. W. Hoy, R. C. North, M. H. Dickson \& J. Barnard. 1988. Analysis of resistance in cabbage varieties to damage by Lepidoptera and Thysanoptera. J. Econ. Entomol. 81: 634-640.

Snedecor, G. W. \& W. G. Cochran. 1980. Statistical methods, 7 th ed. Iowa State University Press, Ames, Iowa.

Received for publication 6 April 1989; accepted 30 January 1990. 